\title{
Fault analysis in power system using power systems computer aided design
}

\author{
Amanze Chukwuebuka Fortune ${ }^{1}$, Amanze Destiny Josiah ${ }^{2}$ \\ ${ }^{1}$ Department of Electrical Engineering, University of Nigeria, Nigeria \\ ${ }^{2}$ Department of Petroleum Engineering, University of Uyo, Nigeria
}

\begin{abstract}
Article Info
Article history:

Received Dec 6, 2019

Revised Mar 4, 2020

Accepted Apr 25, 2020

Keywords:

Circuit breaker

Fault current

Fault voltage

Power system

PSCAD

ABSTRACT

This work presents a fault analysis simulation model of an IEEE 30 bus system in a distribution network. This work analysed the effect of fault current and fault voltage in a distribution system. A circuit breaker was introduced into the system to neutralize the effect of the fault. The system was run on a PSCAD software and results were obtained. The system was monitored based on the start time and the end time of the fault and how well the circuit breaker reacts with those times. Fault occurred from 0.100 to 0.300 seconds before it was removed. At the time fault was not applied (i.e. from 0.00 to 0.100 and from 0.300 to 0.72 ), the circuit breaker was close and became open when fault was applied so as to cut off current flow through the line.The result obtained gave the disruption caused by the fault and the quick response of the circuit breaker in neutralizing it. Results gotten are based on when the circuit breaker is close and no fault is applied and when the circuit breaker is open due to fault. From this work, it was obtained that circuit breakers are very essential in system protection and reliability.
\end{abstract}

This is an open access article under the CC BY-SA license.

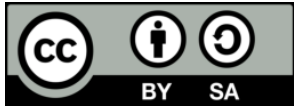

\section{Corresponding Author:}

Amanze Chukwuebuka Fortune,

Department of Electrical Engineering,

University of Nigeria,

Nsukka - Onitsha Rd, Nsukka, Nigeria.

Email: fortuneamanze@gmail.com

\section{INTRODUCTION}

Fault occurrence in power system is inevitable. Hence, in every power system design procedure, these faults are considered and analysed, their likelihood of occurrence is determined and the best ways to handle them are earmarked so as to improve system stability, ruggedness, maintenance cost and reliability.The fault analysis of a power system is required in order to provide information for the selection of switchgear, circuit breakers, and the setting of relays, to be used in the power systems protection. A power system is not static but changes during operation (switching on or of of generators and transmission lines) and during planning operation (addition of generators and transmission lines). Thus, fault studies need to be routinely performed by utility engineers [1-3].

Fault usually occur in a power system due to insulation failure, lightning flashover, physical damage or human error. These faults may either be three-phase in nature involving all three phases in a symmetrical manner, or may be asymmetrical where usually only one or two phases may be involved. Faults may also be caused by either short-circuits to earth or between live conductors, or may be caused by broken conductors in one or more phases. Sometimes simultaneous faults may occur involving both short-circuit fault and brokenconductor fault (also known as open-circuit fault). Balanced three phase faults may be analysed using 
an equivalent single-phase circuit. With asymmetrical three-phase faults the use of symmetrical components helps to reduce the complexity of the calculations as transmission lines are byand-large symmetrical, although the fault may be asymmetrical (not affecting the lines they occur on the same way) [4].

During the operation of power systems, it is desirable to switch on or off the various circuits (e.g.: transmission lines, distributors, generating plants etc) under both normal and abnormal conditions. In earlier days, this function used to be performed by a switch and a fuse placed in series with the circuit $[5,6]$. However, such means of control present two disadvantages. Firstly, when a fuse blows out, it takes quite some time to replace it and restore power supply to the customers [7]. Secondly, a fuse cannot successfully interrupt heavy fault currents that results from modern high voltage and high capacity circuits [8]. Due to these disadvantages, the use of switches and fuses is limited to low-voltage and small capacity circuits where frequent operations are not expected e.g: for the switching and protection of distribution transformers, lighting circuits, branch circuits of distribution lines etc. [9-17]

With the advancement in technology, devices that handle faults better and also switch faster, have been developed. Circuit breakers are designed to manually or automatically switch high voltage, high capacity power components. A circuit breaker can make or break a circuit automatically under fault condition or may be opened manually or by remote control whenever desired under: no-load, full-load and short-circuit conditions. When the contacts of a circuit breaker are separated under fault conditions, an arc is struck between them. The fault current is thus able to continue until the discharge ceases. The production of arc not only delays current interruption but it also generates enormous heat which may cause damage to the system or to the circuit breaker itself. Therefore, the main problem in a circuit breaker is to extinguish the arc within the shortest possible time so that the heat generated by it may not reach a dangerous value [18].Circuit breakers may vary in the type of mechanism or material used for arc quenching and also in the voltage it can operate at safely; in size and in capacity of fault current it can withstand.

Faults cause unreliability and instability in power systems. Unhandled faults cause breakdown of power lines and expensive power system devices (such as generators, transformers and transmission lines, etc) which cause economic meltdowns and even loss of lives. During power line maintenance, it is sacrosanct to be able to isolate the part under maintenance from electrical power for the safety of the power line maintenance engineer. Isolation of power lines is much like switching, there is bound to be dangerous arcs especially when the switching is slow and also when the arc-handling mechanism is not very effective. These arcs damage the switching devices when they are used over some period of time. The aim of this study is to analyse fault in a power system and determine fault- currents and voltages relationships using Power Systems Computer Aided Design (PSCAD). The objectives of this work are to:

- Analyse faults on an International Electrical and Electronics Engineers (IEEE) standard 30-bus test system without protection.

Analyse the operation and characteristics of a vacuum circuit breaker using PSCAD

- Analyse the effect of the application of a vacuum circuit breaker in the protection of a standard IEEE bus system using PSCAD.

International electrical and electronic engineers (IEEE) standard 30 bus system was used in this analysis. The system is $132 \mathrm{kV}-33 \mathrm{kV}$ standard. Its load parameters were established in per unit (pu) and based on 100MVA rating. The IEEE standard is applicable in a physical system and depicts a typical system which is usable in any other experimental analysis. This study and analysis are based on already established experimental data, fault analysis using power system simulation software (PSCAD). The work covers areas of computational analysis of power system devices on a transmission network, fault control algorithms, and circuit breaker operation simulation in software.

Fault analysis in power systems help in the determination of switches' capacities and voltages to be employed in the protection scheme of power systems. During faults very high current magnitudes have to flow through the protective switches even as they attempt to open to isolate the fault. The maximum value of these currents depends on the overall power system parameters such as total available power in each component and the voltages.

Protection in power systems is as important as the system itself. Over the years circuit breakers have been employed in the protection of power lines, generators, transformers and every other component of the power system. The major problems in protection are in the switching on and off of these components. Circuit breakers vary in such parameters as: voltage (because in the open state, they are like capacitors that must have high enough dielectric strength to withstand breakdown as a result of the voltage across it), and current (because in the closed state, they are like conductors which must be able to carry all the dynamic currents of the system). The following are fault studies and circuit breakers analysis existing in literature. 


\section{Modeling of circuit breaker for controlled switching applications using PSCAD/EMTDC}

This presents the electrical and mechanical modelling of a circuit breaker in Power System Computer Aided Design / Electromagnetic Transients including Direct Current (PSCAD/EMDTC) environment. According to [19], for controlled switching applications that mainly occur during load switching and faults, circuit breakers' characteristics plays an important role in determining the instant of closing and opening. The key parameters that can affect the accuracy of circuit breaker switching instants are:

a. Operating time of physical contacts of circuit breaker

b. Rate of decay of dielectric strength (RDDS)

c. Rate of rise of dielectric strength (RRDS)

d. Arcing time

Fault analysis of the $150 \mathrm{kV}$ South Sulawesi transmission system using PSCAD/EMTDC

In the work of [20], short circuit fault was considered as one of the characteristics of transient disturbances in electric power systems that must be addressed by safety equipments. It demonstrates that the increase in occurrence of short circuit generates large electrical currents and at a very low voltage. This research claims to address the simulation of short circuit interruption in a $150 \mathrm{kV}$ transmission line. The method is used to perform the simulation with the help of PSCAD / EMTDC and PWS (Power World Simulator) software's to obtain the characteristic of current and voltage on the $150 \mathrm{kV}$ transmission network in South Sulawesi. It examines the changes in current and voltage during short circuit fault with or without fault impedance and fault location distance.

\section{Analysis of research and development trends in vacuum circuit breakers}

According to [21], several companies in the beginning of the twentieth century, notably General Electric and Westinghouse in the United States, invested significant R\&D manpower and finances into building the knowledge and expertise in vacuum arcs, vacuum contacts, and vacuum interrupters. These efforts resulted in successful deployment of commercial vacuum circuit breakers for medium voltage distribution systems. The companies were also very enthusiastic to continue the main research in extending the applicability of vacuum into higher voltage, sub-transmission and transmission systems. Soon they were to be faced with big disappointment. It turns out that the vacuum interrupters are not easily scalable to higher voltages. Particularly, the electric field breakdown between two contacts in vacuum is not proportional to the contact distance. Although a $0.5 \mathrm{~mm}$ contact gap can withstand approximately $15 \mathrm{kV}$, the gap of $50 \mathrm{~mm}$ will not handle $1500 \mathrm{kV}$, or $1.5 \mathrm{MV}$. The scaling law is not linear and other physical processes stand on the way of using long contact gaps for higher voltages.

The initial excitement diminished and the vacuum switch production companies concentrated on the distribution products with additional applications of low voltage vacuum contactors. Today only a handful of companies maintain production line of commercial vacuum switching products above $36 \mathrm{kV}$ primarily by employing a series combination of interrupters each rated in the $15-36 \mathrm{kV}$ range. This situation might be changing. In this work, it was stated that in last several years of advances, provision has been made on more understanding of the practical issues associated with vacuum switchgear.

Also, the economics of the vacuum interrupter manufacturing changed dramatically, the devices being less expensive, smaller, and more efficient. The work also stated that traditional boundary between the applications of Sulphur HexaFluoride $\left(\mathrm{SF}_{6}\right)$ and vacuum technologies is changing and the recent inquiries of the environmental impact of SF6 also play a role in this process. All said, the vacuum switchgear is a mature technology and still an active industry with dynamically increasing shares of the world markets, production volumes, and more efficient, smaller and better products.

\section{Dynamic simulation of a vacuum switch with PSCAD}

The work of [22] shows that the switching behaviour of the vacuum circuit breaker is different from that of other circuit breakers when the effects of current chopping, dielectric strength of vacuum gap, the arc voltage, the quenching capability of high frequency currents, virtual current chopping and prestrikes. The work demonstrated the above behaviours in simulation using PSCAD. The Vacumm Circuit Breaker (VCB) model developed in this paper uses the variable resistor approach representing frequently switching inductances and capacitances. It also mentions that the other approach to modelling a VCB is by using an ideal circuit breaker which is switched on / off after different criteria have been checked. This work also investigates the stress on a VCB and the energy in the vacuum tube: as current through a VCB is flowing from moment of contact separation until next zero crossing, together with the arc voltage, the energy conversion is very high, dependent on the moment of contact separation. 


\section{RESEARCH METHOD}

\subsection{Methods employed in the analysis simulation}

This research analysis uses PSCAD to simulate fault conditions of a standard IEEE 30-Bus system using the transmission line model line Bergeron of PSCAD which has a graphical user interface for EMTDC simulation and control simulation engine [23]. PSCAD enables users to build a circuit schematic, run simulations, and analyse results, manage data in a fully integrated graphical environment, control and meter so that users can change system parameters during the simulation run and can obtain immediate results $[24,25]$. PSCAD comes with a library of models that have been programmed and tested, ranging from simple passive elements, control functions and more complex models such as electric machines, FACTS device, transmission lines, transformers and cables. EMTDC (Electromagnetic Transient, Including DC) proposes and solves differential equations in time domain. The solution is calculated based on fixed time step, and the program structure allows for the representation of the control system.

The VCB model used in this work is written in FORTRAN77 code. It is possible to create own models and integrate them into the component library of PSCAD if they are not already available. Parameterization of the VCB is done by filling the input mask. Other simulation software might have other means of presenting these.

\subsection{VCB model}

The VCB in this paper is modeled by a variable resistance, this is important for considering the arc voltage. Input parameters are: voltage, current and switching command. The output parameter is the value of resistance. Furthermore, there are several parameters which can be admitted by the input mask as shown in Table 1.

Table 1. Input mask of VCB

\begin{tabular}{ll}
\hline \multicolumn{2}{c}{ Configuration } \\
\hline Maximum Voltage $[\mathrm{kV}]$ & $60[\mathrm{kV}]$ \\
Metal vapour arc voltage [V] & $25[\mathrm{~V}]$ \\
Resistance (closed) [ohm] & $80 \mathrm{e}-6[\mathrm{ohm}]$ \\
Resistance (open) $[\mathrm{ohm}]$ & $100 \mathrm{e} 6[\mathrm{ohm}]$ \\
Frequency [Hz] & $60[\mathrm{~Hz}]$ \\
Slope of dielectric recovery $[\mathrm{kV} / \mathrm{ms}]$ & $30[\mathrm{kV} / \mu \mathrm{s}]$ \\
Initial value of dielectric strength $[\mathrm{kV}]$ & $0[\mathrm{kV}]$ \\
Slope of dielectric strength $[\mathrm{kV} / \mu \mathrm{s}]$ & $50[\mathrm{kV} / \mu \mathrm{s}]$ \\
Initial value of dielectric stsrength $[\mathrm{kV}]$ & $0[\mathrm{kV}]$ \\
Current quenching capability $[\mathrm{A} / \mu \mathrm{s}]$ & $80[\mathrm{~A} / \mu \mathrm{s}]$ \\
\hline
\end{tabular}

Here, electrical parameters are defined, such as resistance in closed and open position and maximum voltage. Additionally, value of arc voltage, rise in dielectric strength and rise in dielectric recovery can be chosen. The arc voltage is modeled as a constant value in order to simplify the model. The corresponding value of resistance is calculated by (1)

$$
\mathrm{r}=\mathrm{V}_{\mathrm{arc}} / \mathrm{I}_{\mathrm{VCB}}
$$

Both dielectric recovery mechanisms are modeled using (2).

$\mathrm{V}_{\text {contact }}(\mathrm{t})=30 \mathrm{kV} / \mathrm{ms}$.t (effective only at moment of contact separation)

$\mathrm{V}_{\text {dielectric }}(\mathrm{t})=50 \mathrm{kV} / \mu \mathrm{s}$.t (effective at current separation)

$$
\text { Generally, } V=a . x
$$

Where:

$\mathrm{x}=$ contacts distance

$\mathrm{a}=$ slope of di-electric

These values are limited by the maximum voltage of VCB $(60 \mathrm{kV})$. The closing of contacts is modeled by $60 \mathrm{kV}-\mathrm{V}_{\text {contact }}$ A function checks di/dt of current at every zero crossing to consider the current quenching capability of the vacuum space. The value is set to a maximum of $80 \mathrm{~A} / \mu \mathrm{s}$. If this value is exceeded, current will go on flowing till the next current zero.

This VCB model will be employed in the standard IEEE 30 bus system for fault studies. The model block is as shown in Figure 1 and the label "BRK" represents the control signal as shown in Figure 2. Here 
the control signal is attached to the output of the timed fault logic block so as to trigger the circuit breakers on the line as soon as the fault occurs.

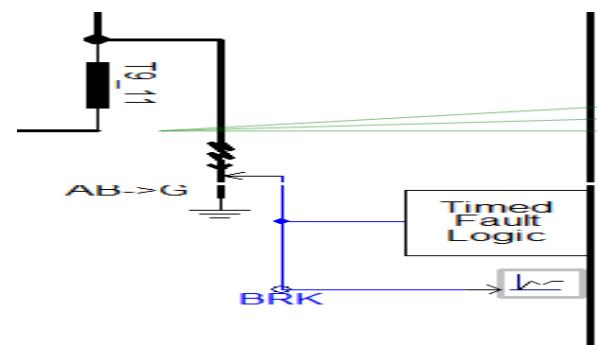

Figure 1. The timed fault logic with its signal output linking "BRK"

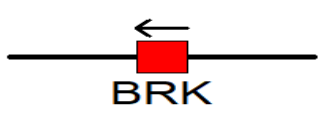

Figure 2. The VCB model Block

\subsection{The fault model}

Table 2 is showing the fault block in PSCAD library is used to create a double line-ground fault (shown as AB G). The fault block can simulate three lines (LLL) fault, double line to ground (LLG) fault, double line (LL) fault, double line to ground (LG) fault, three line to ground (LLLG) fault. In this study, LLG was chosen for the comparism between a healthy and faulty line.

Table 2. The fault mask

\begin{tabular}{llll}
\hline \multicolumn{1}{c}{ Fault Type } & \multicolumn{3}{c}{ Three Phase Fault } \\
& \multicolumn{3}{c}{ Fault Resistances } \\
\hline General & Yes & Fault ON Resistance & $0.01[\mathrm{ohm}]$ \\
Is Phase A in Fault? & Yes & Fault OFF Resistance & $100 \mathrm{E} 6[\mathrm{ohm}]$ \\
Is Phase C in Fault? & No & & \\
Is Phase C in Fault? & Yes & & \\
Is this Fault to Neutral? & Yes & & \\
\hline
\end{tabular}

The fault model block in Figure 2; placed on T9_11 $(33 \mathrm{kV})$. The fault was set to occur 0.1 seconds into the simulation and be removed after 0.3 seconds of occurrence.

The results from the fault trigger will be analysed later as well as the data used to compute the currents and voltages during fault.

Figure 3 is the standard IEEE bus with fault and without protection. It is easy to see that the fault affects every other transmission line, generators and every other component attatched to the system.

Figure 4 shows the same 30 bus system but with fault protection circuit breaker placed on the line of occurrence.

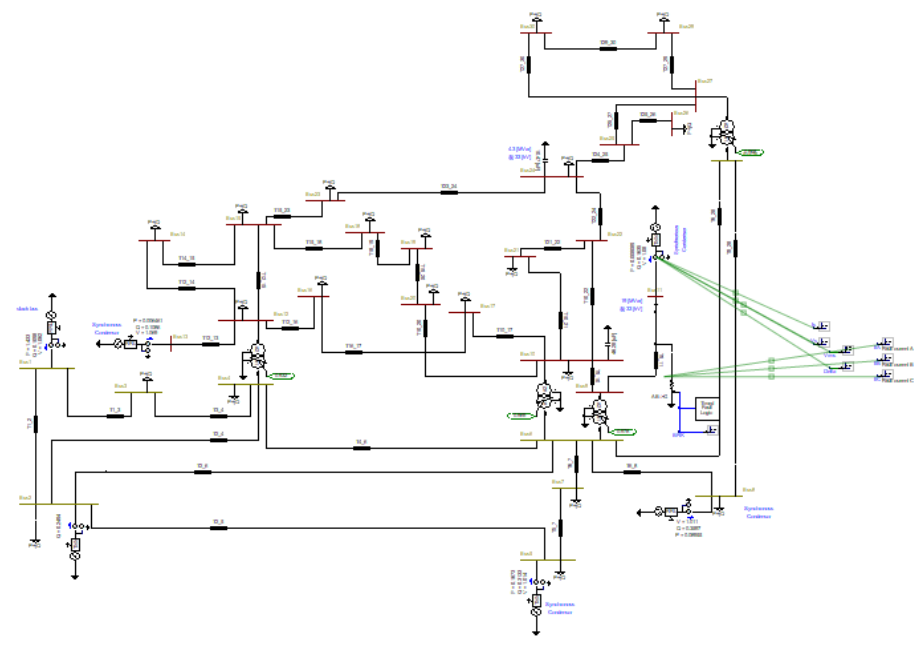

Figure 3. Fault placed on T9_11 without protective circuit breaker. 


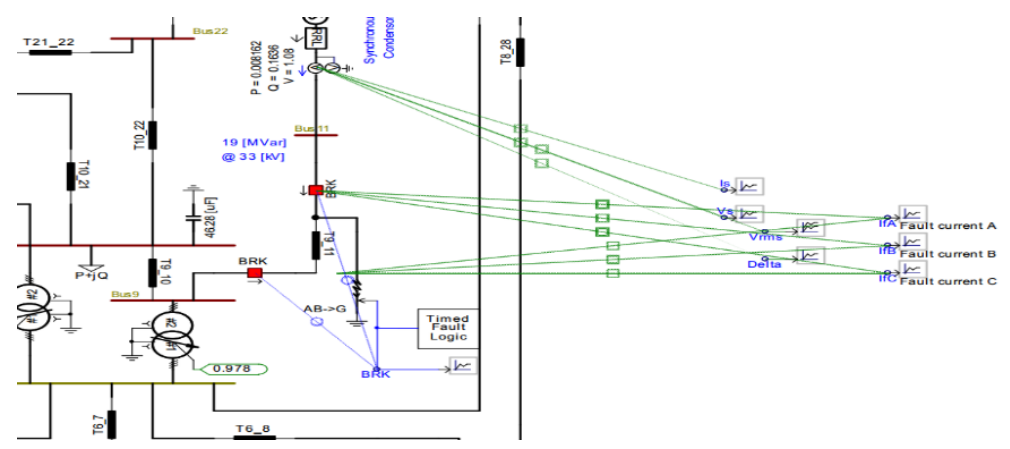

Figure 4. A bolder view of the TL with fault

Loads are modelled as a constant PQ load with parameters as shown in Table 3.

Table 3. Load characteristics of IEEE 30-bus system

\begin{tabular}{cccccc}
\hline Bus & $\mathrm{P}[\mathrm{pu}]$ & $\mathrm{Q}[\mathrm{pu}]$ & Bus & $\mathrm{P}[\mathrm{pu}]$ & $\mathrm{Q}[\mathrm{pu}]$ \\
\hline 2 & 0.217 & 0.127 & 17 & 0.090 & 0.058 \\
3 & 0.024 & 0.012 & 18 & 0.032 & 0.009 \\
4 & 0.076 & 0.016 & 19 & 0.095 & 0.034 \\
5 & 0.942 & 0.190 & 20 & 0.022 & 0.007 \\
7 & 0.228 & 0.109 & 21 & 0.175 & 0.112 \\
8 & 0.300 & 0.300 & 23 & 0.032 & 0.016 \\
10 & 0.058 & 0.020 & 24 & 0.087 & 0.067 \\
12 & 0.112 & 0.075 & 26 & 0.035 & 0.023 \\
14 & 0.062 & 0.016 & 29 & 0.024 & 0.009 \\
15 & 0.082 & 0.025 & 30 & 0.106 & 0.019 \\
16 & 0.035 & 0.018 & & &
\end{tabular}

The above data were used to model every transmission line and load in the system. They are based on 100MVA.

\section{RESULTS AND ANALYSIS}

3.1. Software analysis of an IEEE 30 bus system with fault at T9_11 without protection.

The graphs give a pictorial idea of the values (bus voltage, bus current, fault current separate for each phase, rms voltage, fault signal) expected form the fault studies. From Figure 5, it is seen that fault occurred on two lines and the instance of fault occurance, the voltage in the two lines became zero.

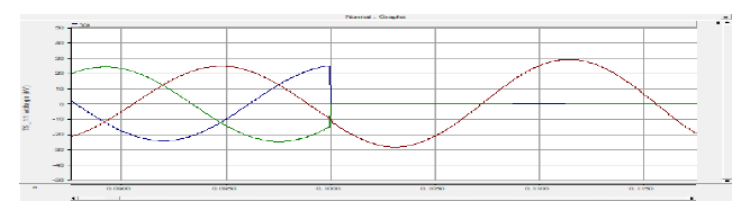

Figure 5. Bus voltage at the instant of fault occurrence

Figure 6 depicts the effect of the fault on the RMS voltate of the system. The fault seen to occur from the $0.1 \mathrm{sec}$ to $0.3 \mathrm{sec}$ gets to give more detals on the very short duration of the occurrence of fault.

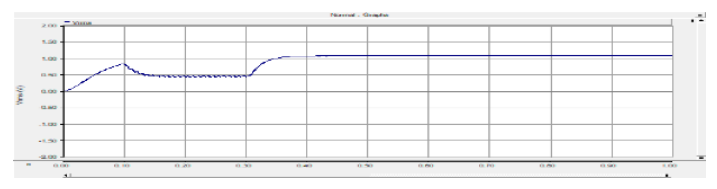

Figure 6. RMS Voltage during the period of fault 
The effect on of the fault on the current on each line as ssen in Figures 7, Figure 8 and Figure 9 gives the effect of the fault current on the lines. The faulted line which is the phase A and phase B has its current spike to a value very high when compared to its normal current rate. The fault current has no effect on phase $\mathrm{C}$ because it had no fault.

Figure 10 is the complete waveform of the transmisssion line with the three phases indicating the instant of fault occurrence which is between $0.1 \mathrm{sec}$ to $0.3 \mathrm{sec}$. The wave depicts the effect of the two phases with fault. The faulted lines green and blue had its current spike during fault occurence and became steady back to normal after fault was gone. The Red phase had no fault.

Figure 11 is the indication of the immediate removal of the fault from the system. The fault which could be caused by wind can seize when the atmosphere is okay and would relese the bridging lines. It can be seen that the two line with the fault had an irregular curve before becoming steady. Without protection, there may not be any ecovery from the fault occurance.

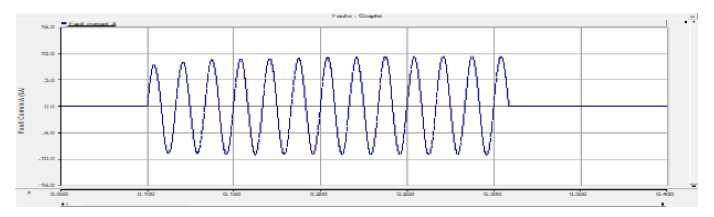

Figure 7. Fault current on phase A without protection

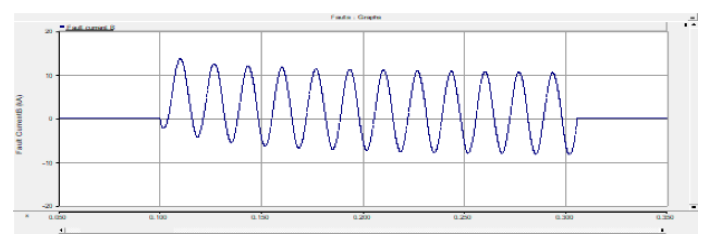

Figure 8. Fault current on phase B without protection

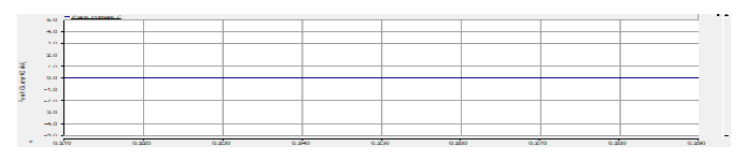

Figure 9. Fault current on phase $\mathrm{C}$ without protection

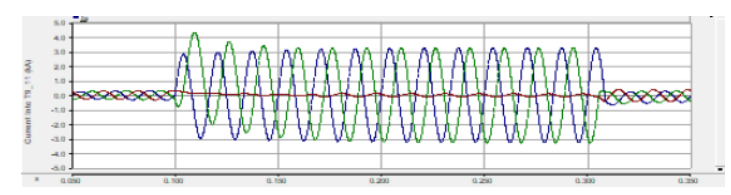

Figure 10. Transmission line current in the period of fault occurrence

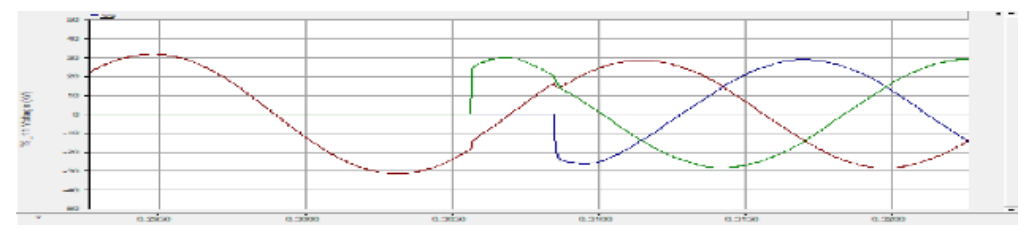

Figure 11. Bus voltage at the instant of fault removal 
What is seen in the above graphs is a clear indication of the dangers of an unprotected power system. It may look simple but the two lines with fault will cause drastic load changes not just on the bus and the remaining line which the fault is directly attached to but every other component in that system.

\subsection{Software analysis of an IEEE 30 bus system with fault at T9_11 with protective VCB.}

Figure 12 is the effect of the quick removal of fault on the transmission line due to the effect of circuit breakers. The circuit breaker annuls the effect of the fault instantly preventing equipment destruction.

The current chopping limit set in the model is $0.0 \mathrm{kA}$. This results in the phenomenon observed in the waveforms of the faulty system with protection. An ideal VCB would have caused no disturbances on the system during fault. However, there are disturbances on even the healthy line due to the parameters of the VCB which are not ideal, for instance, the vacuum dielectric strength, the dielectric recovery, the voltage across the contacts etcetera. When the fault occurred, the attempt by the VCB to isolate it was distorted due to the arc established by the separation of the contacts which heat up the region, the time of distortion seen is the time dielectric recovery of the VCB. This same thing happens when the VCB is de-energized after the fault removal. The fault signal is given in Figure 13.

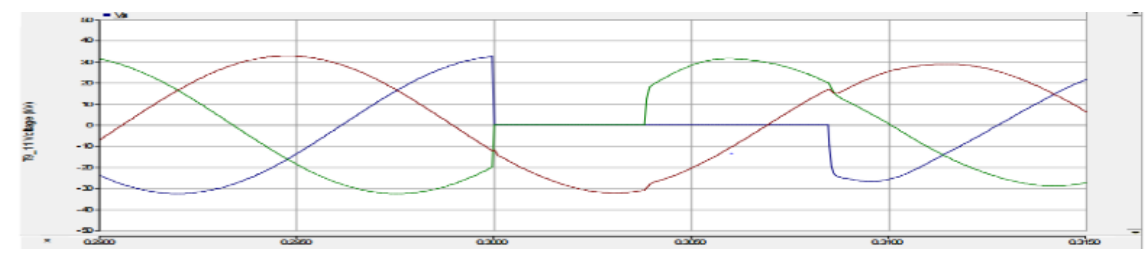

Figure 12. Bus Voltage at the instant of fault and fault removal

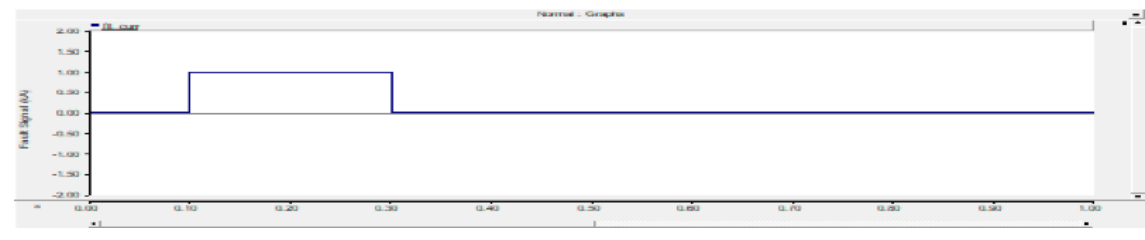

Figure 13. The fault signal

\section{CONCLUSION}

Every device obeys Newton's first law of motion and the VCB movable contacts are not exceptions. Under heavy loads such as short-circuits, opening and closing of circuit breaker contacts generates an arc around the contact regions which heats up the contacts. If the fault is not cleared early enough by protective elements such as the circuit breaker, severe damages would be done on the system which will not only be catastrophic and extremely dangerous, but also costly.It is therefore, extremely important to perform fault studies on every power system, in order to determine the ratings of the respective protective elements employed. The importance of CBs in power systems is extremely important and the VCB in particular has a very good fault error clearing capabilities, ease of installation and environmentally friendly. Concerned industries should pioneer research programs in the area of development of high voltage VCBs in our institutions and research centers. Every component of our power system should be protected from fatal and total failures usually caused by faults and accidents on the transmission and distribution sections. To protect failures in our national grid, power system protection engineers should be employed to examine and perform adequate fault study on the system.

\section{REFERENCES}

[1] L. Xingping, Distribution transformers health condition monitoring and evaluation methods, Chongqing, 2013.

[2] State Grid, Q-GDW 11190-2014 high overload capacity of rural power distribution transformers technical guideline, China Electric Power Press, Beijing, 2014.

[3] IEEE Standard C57.91-1995 IEEE Guide for Loading Mineral-Oil-Immersed Transformers.

[4] G. Swift, Z. Zhang, "A different approach to transformer. thermal modeling", IEEE Transmission and Distribution Conference, New Orleans, Apr 1999. 
[5] IEC (International Electrotechnical Commission) Standard 354Second Edition, 1991-09, Loading guide for oilimmersed power transformers, pp. 143-145, 1991.

[6] M. Klasen-Memmer and H. Hirschmann, "Liquid crystal materials for devices", IN J. Chen, W. Cranton and M Fihn (eds.) "Handbook of Virtual Display Technology", Springer-Verlag Berlin Heidelberg, 2012.

[7] J. J. Grainger and W. D. Stevenson, Power system and analysis, Tata Mc- Graw-Hill, 2005.

[8] E. Acha., V. Agelidis, O. Anaya-Lara, T. Miller, Power electronic control in electrical systems, Newness Power Engineering Series 2002.

[9] SadohJ, PhD, "Thesis on power system protection: investigation of system protection schemes on the 330KV of Nigeria transmission network," University of Benin, Benin City, 2006.

[10] L.P. Singh, Advanced power system analysis and dynamics, Wiley, New York, 1983.

[11] Anderson, Paul M, Analysis of faulted power systems, Iowa State Press, Ames, 1973.

[12] H.E. Brown and C.E. Person, "Short circuit studies of large systems by the impedance matrix method," Proc. PICA, pp. 335, 1967.

[13] S. Bakanagari, A. Mahesh Kumar, M. Cheenya, "Three phase fault analysis with auto reset for temporary fault and trip for permanent fault," Int. Journal of Engineering Research and Applications, vol. 3, no. 6, pp. 1082-1086, 2013.

[14] G. Vladimir, Electrical relays principle and applications, Taylor and francis group publication, 2006.

[15] D. Miroslav, Fault analysis in power systems by using the fortescue method, TESLA Institute, 2009.

[16] J. Zhu. "Analysis of transmission system faults the phase domain," Texas A\&M University. Master Thesis, 2004.

[17] M. Aleksandar, "Analysis of asymmetrical faults in power systems using dynamic phasors," IEEE Transactions on Power Systems, vol. 15, no. 3, pp. 1062-1068, 2000.

[18] V. Gamit, et al, "Fault analysis on three phase system by auto reclosing mechanism," International Journal of Research in Engineering and Technolog, vol. 4, no. 5, pp. 292-298, 2015.

[19] T. Mushiri and C. Mbohwa, "Research on the use of MATLAB in the modeling of 3-phase power systems," Proceedings of the World Congress on Engineering (WCE 2015), vol. 1, 2015.

[20] C. Vijaya Tharani, et al, "MATLAB based simulations model for three phases power system network," Int. Journal for Research in Applied Science \& Engineering Technology, vol.4, no. 11, pp. 502-509, 2016.

[21] A. Adly, M. Christopher, G. Fallon, L. David, "A fault location technique for rural distribution feeders," IEEE transaction on Industry Application, vol. 29, no. 6, pp. 1170-1175, 1993.

[22] N. Amjady, "Design and implimentation of a fault diagnosis system for transmissin and subtransmission networks", IEEE paper on tranmission \& distribution con. Exp., vol. 2, pp. 69-704, 2003.

[23] J.A. Halluday, C.H. Shih, "Resonent overvoltage phenomena coused by transmission line fault," IEEE trans. Power apparatus \& system, vol. 104, no. 9, pp. 2531-2539, 1985.

[24] D. C. Yu, D. Chen, S. Ramasamy and D. G. Flinn, "A windows based graphical package for symmetrical components analysis," IEEE Transactions on Power Systems, vol. 10, no. 4, pp. 1742-1749, 1995

[25] M. Yuen Chow, S. Leroy, "A novel approach for distribution fault analysis," IEEE Transactions on Power Delivery, vol.8, no. 4, pp. 1882-1889, 1993.

\section{BIOGRAPHIES OF AUTHORS}

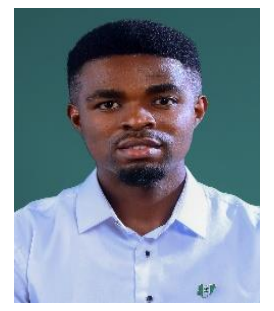

Fortune Chukwuebuka Amanze is a graduate researcher at the Department of Electrical Engineering, University of Nigeria, Nsukka in Enugu State Nigeria. His research interests are in Power Sytems, Power Electronics and Control Systems Engineering.

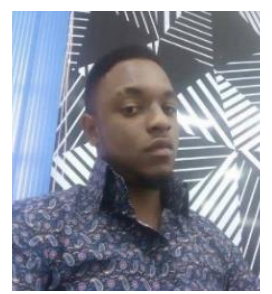

Destiny Josiah Amanze is a graduate researcher who has a flair for Energy systems and efficient utilization of Energy. His research approach is aimed at seeking alternatives to already existing energy sources and efficient use of current energy sources to increase productivity. 